This is a peer-reviewed article published in 2012 in volume 5, number 2, pages 59-73, of the journal Current Development in Oceanography. However, for unknown reasons, in 2019 the publisher (Pushpa Publishing House, Allahabad, India) deleted this entire journal and all of its articles from its website (www.pphmj.com). During its existence, this journal was published only online. Therefore, to make the attached article permanently available to the scientific community, it is hereby submitted to MarXiv. 


\title{
TEMPERATURE, DESICCATION, AND SPECIES PERFORMANCE TRENDS ALONG AN INTERTIDAL ELEVATION GRADIENT
}

\author{
Lindsay K. Eckersley and Ricardo A. Scrosati* \\ Department of Biology \\ Saint Francis Xavier University \\ Antigonish, Nova Scotia B2G 2W5 \\ Canada \\ e-mail: rscrosat@stfx.ca
}

\begin{abstract}
This study investigated the effects of intertidal elevation on ecologically relevant temperature traits and the intensity of organism desiccation during low tides on a subpolar NW Atlantic shore. The goal was to relate those descriptors of environmental stress to elevational changes in the growth of dominant sessile species (algae and mussels) that influence overall community structure. In-situ measurements taken at the low, middle, and high intertidal zones revealed that daily temperature maxima, daily temperature range, and desiccation rate increased significantly from low to high elevations. Conditions were especially stressful at the high zone, as the highest temperature $\left(47^{\circ} \mathrm{C}\right.$, recorded during aerial exposure at low tide) more than doubled seawater temperature and desiccation rate surpassed 90\%. Transplant experiments showed that seaweed (Ascophyllum nodosum) and mussel (Mytilus edulis) growth rate decreased
\end{abstract}

(C) 2012 Pushpa Publishing House

Keywords and phrases: environmental stress, intertidal, mussel, seaweed.

*Corresponding author

Communicated by Hyo Choi

Received August 21, 2012 
dramatically from low to high elevations. Therefore, although subpolar shores are mostly known for their harsh winter conditions, the pronounced vertical stress gradient that characterizes the intertidal zone during ice-free months also plays a major role in determining spatial changes in benthic species performance. Our study also suggests that inferring stress differences between habitats based on growth data from transplanted specimens may be a useful field method to further develop stress ecological theory.

\section{Introduction}

Intertidal habitats are the coastal areas occurring between the highest and lowest tides. Due to the periodic alternation of high and low tides on a daily basis, intertidal areas are exposed to aerial conditions for longer periods of time as elevation increases. As a result, key ecological factors such as temperature and organism desiccation $[10,27]$ reach extreme values towards high elevations. Thus, for intertidal communities considered as a whole, environmental stress generally increases from low to high elevations. Since such abiotic changes occur in a few meters on a vertical basis (the intertidal range), intertidal elevation gradients have been useful model systems for experimental research on the role of stress in community organization [16].

Despite the existing knowledge on intertidal elevational trends in temperature and desiccation, direct measurements in combination with measurements on species performance are rare. This is especially true for subpolar (cold-temperate) shores, which are best known for their harsh winter conditions $[3,21,23,24]$, but for which less information exists on abiotic conditions in relation to changes in species growth across elevations. Such knowledge would be especially valuable for basal species, also known as primary-space holders (sessile species attached to the substrate), because such organisms sustain intertidal communities through the consumers that feed on them $[15,17]$ or through the provision of suitable microhabitat for the colonization of smaller species $[2,12]$.

For the present study, we collected field data from the NW Atlantic coast to investigate the effects of intertidal elevation on ecologically important 
temperature traits and on the intensity of organism desiccation during low tides. In addition, we investigated elevation effects on the growth of two dominant basal species (a seaweed and a mussel) evaluated through experimental transplants across elevations using organisms collected from a common source. Our hypotheses were that desiccation and ecologically relevant temperature traits (maximum values and range of variation) would increase with intertidal elevation, but that seaweed and mussel growth rates would decrease with elevation.

\section{Materials and Methods}

\section{Study shore}

We did all experiments and measurements along a $4 \mathrm{~km}$ stretch of shoreline between Doctor's Brook $\left(45^{\circ} 47^{\prime} \mathrm{N}, 62^{\circ} 05^{\prime} \mathrm{W}\right)$ and Arisaig $\left(45^{\circ} 46^{\prime} \mathrm{N}, 62^{\circ} 10^{\prime} \mathrm{W}\right)$, on the northern coast of Nova Scotia, Canada. There, the intertidal substrate is volcanic bedrock. We used areas that are protected from direct incoming swell by a variety of natural rocky formations. In these habitats, maximum water velocity (an index of wave exposure) measured with dynamometers (see design in [1]) range between 2.9-4.1 $\mathrm{m} \mathrm{s}^{-1}$ [25]. The maximum tidal amplitude (vertical distance between the highest and lowest tides) is approximately $1.8 \mathrm{~m}$. For our study, we divided this intertidal range into three equal elevation zones (low, middle, and high intertidal zones).

\section{Temperature}

We deployed 3 submersible loggers (StowAway TidbiT, Onset Computer, Pocasset, Massachusetts, USA) at each of the low, middle, and high intertidal zones to measure temperature dynamics between 21 July and 20 August 2006. Loggers were set to take readings every 6 minutes. The loggers were secured with plastic cable ties to metallic hooks affixed with marine epoxy (A-788 Splash Zone Compound, Z-Spar, Los Angeles, California, USA) to the rocky substrate in a way that loggers made almost no contact with the substrate. For data analyses, we selected temperature traits that are ecologically relevant because they represent extreme events and range of variation [27]: mean daily maximum, daily mean, mean daily 
minimum, and mean daily range (daily range being the difference between the daily maximum and minimum values of temperature). To investigate elevation effects on these temperature traits, we ran a Kruskal-Wallis analysis of variance (due to violation of parametric assumptions) separately for each trait, followed by Mann-Whitney pairwise tests to compare elevation zones [20].

\section{Desiccation}

We quantified desiccation during low-tide conditions at the low, middle, and high intertidal zones using 20-cm-long apical frond fragments of the fucoid seaweed Ascophyllum nodosum. This macroalga is the most abundant intertidal species in terms of coverage and biomass on the study shore [25]. On 9 October, at low tide, we collected 30 of such frond fragments at random from the entire intertidal range and randomly attached 10 of them at each of the low, middle, and high intertidal zones by securing the frond fragments with strings to nails drilled into the rocky substrate. On 10 October, we collected the frond fragments just before the rising tide reached each elevation zone, thus having allowed for maximum desiccation to occur at each zone. Immediately after collecting the algal fragments at each zone, we placed them in plastic bags that were kept tightly sealed inside a cooler to avoid any further desiccation. Once all frond fragments were collected, we transported them quickly to the laboratory, where we measured their wet and desiccated biomass. We calculated the percent desiccation for each algal fragment as:

$$
\% \text { desiccation }=\frac{\text { wet biomass }- \text { desiccated biomass }}{\text { wet biomass } * \text { mean proportional water content }} * 100
$$

The "desiccated biomass" of an algal fragment was its mass measured at the end of the corresponding low-tide conditions at each elevation zone, that is, the algal fragment's mass weighed right after the fragments arrived to the lab inside the plastic bags. The "wet biomass" of an algal fragment was its mass after fully re-hydrating the fragment by placing it in a container with seawater until constant mass was achieved. To calculate the "mean proportional water content" of Ascophyllum nodosum fronds, first we 
measured the wet biomass of 30 apical frond fragments (different from those described above) collected randomly from the shore, then we measured their "dry biomass" after fully dehydrating them at $60^{\circ} \mathrm{C}$ for $48 \mathrm{~h}$ and, finally, we applied the following formula:

$$
\text { mean proportional water content }=\frac{\sum \frac{(\text { wet biomass }- \text { dry biomass })}{\text { wet biomass }}}{30}
$$

Therefore, the value of percent desiccation for each of the algal fragments deployed in the field indicates the percentage of the total water content of each fragment that was lost due to desiccation during the low tide at the corresponding elevation zone. To investigate elevation effects on percent desiccation, we ran a parametric analysis of variance, followed by Tukey pairwise tests to compare elevation zones [20].

\section{Seaweed and mussel growth}

To test the effects of intertidal elevation on seaweed and mussel growth, we selected Ascophyllum nodosum and Mytilus edulis. Both species occur along the entire range of intertidal elevation [25]. M. edulis is the blue mussel and is one of the most common sessile invertebrates on the study shore; genetic analyses have found that this is the only species of intertidal mussel occurring there [25]. To determine elevation effects on algal and mussel growth, we measured the growth in length of specimens that were transplanted from a common source to the low, middle, and high intertidal zones while permanently excluding the effects of interspecific interactions (competition, facilitation, herbivory, or predation) to avoid confounding biological factors.

To achieve that, first we randomly collected seaweed and mussel specimens from the entire intertidal range, mixing the specimens (separately for each species) to produce a common pool of organisms for each species. Then, separately for each species, we transplanted specimens to the low, middle, and high intertidal zones by randomly assigning 10 organisms to 10 experimental cages $(10 \mathrm{~cm} \times 10 \mathrm{~cm} \times 3 \mathrm{~cm}$, made with $0.6 \mathrm{~cm} \times 0.6 \mathrm{~cm}$ galvanized-iron mesh, Brico Tool, Brampton, Ontario, Canada) that were 
attached to each elevation zone (thus producing 30 cages for each species). The cages ensured that interspecific interactions between the transplanted specimens and other intertidal organisms did not occur. The cages were affixed to the rocky substrate using marine epoxy (A-788 Splash Zone Compound). For seaweeds, cages were established at random at each elevation zone along the study shore. For mussels, cages were established at random along the shore in 10 groups that represented 10 statistical blocks, each group consisting of 1 cage placed at each elevation zone. We started the experiment on 7-10 July for seaweeds and 21-26 July for mussels and ended it after 4 weeks for both species. To measure growth, we measured the initial and final length of seaweed fragments to the nearest $1 \mathrm{~mm}$ with a ruler, and the initial and final length of mussels to the nearest $0.05 \mathrm{~mm}$ with a caliper. The initial length of algal apical fragments was $156.9 \pm 2.0 \mathrm{~mm}$ (mean $\pm \mathrm{SE}$, $n=300$ ), while the initial length of mussels was $33.4 \pm 0.5 \mathrm{~mm}$ (mean $\pm \mathrm{SE}$, $n=300$ ). To be able to identify the same specimens at the end of the experiment, we initially marked the seaweed fragments by tying coloured strings to them and the mussels by glueing numbered tags to their shells.

For each algal specimen, growth rate during the experiment was calculated as the difference between final and initial length. To investigate elevation effects on seaweed growth rate, we ran a Kruskal-Wallis analysis of variance (due to violation of parametric assumptions) followed by MannWhitney pairwise tests to compare elevation zones [20]. For each mussel, growth rate was also calculated as the difference between final and initial length. In mussels, length increments have a quadratic dependency on organism size [13]. Thus, to remove any statistical influence of initial length on our measures of mussel growth rate, we first determined the quadratic relationship between initial length and absolute growth rate (the difference between final and initial length) through nonlinear least-squares regression [20]. Once the quadratic relationship was obtained, we calculated the statistical residual for each mussel as the difference between the observed value of absolute growth rate and the value predicted by the quadratic relationship for each mussel according to its initial length. In that way, those statistical residuals represented values of size-independent growth rate. To 
investigate elevation effects on mussel growth rate, we ran a randomizedblock analysis of variance on the above mentioned growth residuals followed by Tukey pairwise tests to compare elevation zones [20]. In Ascophyllum nodosum, initial length influences only $5 \%$ of the absolute growth rate [8], so it was not necessary to apply to its growth data the adjustment that we applied to the mussel growth data.

\section{Results}

Results for the measured temperature traits are summarized in Table 1. The extreme maximum temperature increased markedly from low to high elevations, with the value for the high intertidal zone being $6 \%$ higher than for the middle zone and $32 \%$ higher than for the low zone. Mean daily maximum temperature differed significantly among elevations $\left(H_{2}=123.9\right.$, $P<0.001)$, consistently increasing from low to high elevations $(P<0.001$ for the two relevant pairwise tests: low-middle and middle-high). Mean daily temperature also differed significantly among elevations $\left(H_{2}=915.0\right.$, $P<0.001)$, consistently increasing from low to high elevations $(P<0.001$ for the two relevant pairwise tests: low-middle and middle-high). Mean daily minimum temperature also differed significantly among elevations $\left(H_{2}=78.7, P<0.001\right)$, consistently decreasing from the low to the middle zone $(P<0.05)$ and from the middle to the high zone $(P<0.001)$. The mean daily range of temperature also differed significantly among elevations $\left(H_{2}=147.5, P<0.001\right)$, consistently increasing from low to high elevations $(P<0.001$ for the two relevant pairwise tests: low-middle and middle-high). It is worth noting that the mean daily range of temperature for the high intertidal zone was $64 \%$ higher than for the middle zone and an impressive $387 \%$ higher than for the low zone.

Percent desiccation differed significantly among elevations $\left(F_{2,26}=\right.$ $840.4, P<0.001)$, increasing consistently from the low to the high intertidal zone $(P<0.05$ for the two relevant pairwise tests: low-middle and middle- 
high; Figure 1). While the transplanted fragments lost relatively little water (close to 20\%) during low tide at the low intertidal zone, they lost a considerable amount $(>90 \%)$ at the high zone (Figure 1).

Seaweed growth rate differed significantly among elevations $\left(H_{2}=151.8, P<0.001\right)$, decreasing consistently from the low to the high intertidal zone $(P<0.001$ for the two relevant pairwise tests: low-middle and middle-high; Figure 2). While average growth was positive at the low intertidal zone, it became negative at the high zone (Figure 2).

Mussel growth rate differed significantly among elevations $\left(F_{2,181}=\right.$ $19.1, P<0.001)$, decreasing consistently from the low to the high intertidal zone $(P<0.001$ for the two relevant pairwise tests: low-middle and middlehigh; Figure 3). Average mussel growth rate turned from positive at the high intertidal zone to negative at the low zone (Figure 3).

\section{Discussion}

Temperature and desiccation are major factors affecting intertidal species, especially those that are sessile and cannot move away from areas temporarily experiencing harsh conditions [16]. Thus, investigating vertical trends in those abiotic variables is essential to understanding elevational changes in species performance. Our field data have revealed that both temperature and desiccation change dramatically along the intertidal gradient from low to high elevations. For temperature, daily maximum values and range of variation are closely associated with stressful conditions [27], and all such indicators were clearly highest at the high intertidal zone. The same was true for desiccation rate, which peaked at the high zone. Such results are a logical consequence of high elevations experiencing aerial conditions for long periods during low tides in warm summer days.

It was particularly revealing that desiccation reached such strong values (>90\%) at high elevations, which left algae holding a minimum fraction of their full water content shortly before the rising tide reached the high shore 
again. Likewise, while mean daily maximum temperature also peaked at high elevations, the highest absolute value $\left(46.7^{\circ} \mathrm{C}\right)$ more than doubled seawater values occurring in summer on the study shore (around $20^{\circ} \mathrm{C}$ ). Average environmental conditions are important for species performance, but extreme values often determine widespread mortality events [7]. In fact, the combination of high desiccation and temperature is known to cause reduced growth and, in extreme cases, partial thallus mortality and biomass losses in intertidal seaweeds $[5,22]$. Therefore, high stress emerges as the likely cause of the pronounced biomass losses experienced by the algal fragments experimentally transplanted to the high intertidal zone. Such losses could have been facilitated by the relatively brittle nature of highly desiccated algal thalli, which are susceptible to breakage by the waves of incoming tides before rehydration can make thalli flexible again [11]. Strong abiotic stress also plausibly explains the marked decrease in mussel growth rate recorded towards high elevations. Negative growth rates resulted in this case from shell margin erosion. During low tides, intertidal bivalves respire anaerobically, which produces succinic acid that breaks down calcium carbonate in the shell $[6,19]$. Such a process could be especially prevalent during the long emersions at high elevations, making the thin shell margins prone to erosion as organisms are battered by waves during high tides.

Despite the detrimental effects of high-intertidal conditions on the growth rate of individual algae and mussels, these organisms can indeed occur at high elevations [25]. However, they do not occur individually, but in dense aggregations or in crevices. Organism clumping or occurrence in crevices have been shown to help retain moisture and reduce heat stress during low tides among the organisms living in the group [22, 28, 29]. Those are, in fact, ecological strategies that intertidal organisms have evolved to successfully colonize and persist under harsh conditions [14].

The results of our study also have practical applications. Environmental stress is one of the most important factors determining species performance and community organization $[4,18,26]$. Thus, being able to accurately quantify stress in nature is central to developing stress ecological theory and 
testing it experimentally. However, overall abiotic stress results from several abiotic variables acting in combination on organisms, which often difficult the determination of stress differences across habitats due to logistic limitations in measuring each variable. Instead, measures of species performance (such as growth) integrate all abiotic effects into a single measure and accurately describe what organisms are actually experiencing. The intertidal elevation gradient is known to exhibit a vertical gradient of environmental stress [16], which was clearly supported by our temperature and desiccation data. The fact that our seaweed and mussel growth data were so clearly related negatively to the intertidal stress gradient suggests that transplanted organisms may represent useful tools to accurately describe stress gradients in nature. Collecting organisms for transplants from a common source spanning targeted habitats, as done in our study, will be important to remove beforehand the potential confounding effects of local adaptations [9] on growth measures.

In conclusion, the results of the present study strongly support our hypotheses. Although subpolar shores are mostly known for their harsh winter conditions, which severely limit intertidal life, the pronounced vertical stress gradient that characterizes the intertidal zone during ice-free months also plays a major role in determining spatial changes in species performance.

\section{Acknowledgements}

Our research was supported by grants awarded to R. A. S. by the Canada Research Chairs (CRC) program, the Natural Sciences and Engineering Research Council (NSERC, Discovery Grant), and the Canada Foundation for Innovation (CFI).

\section{References}

[1] E. C. Bell and M. W. Denny, Quantifying wave exposure: a simple device for recording maximum velocity and results of its use at several field sites, J. Exp. Mar. Biol. Ecol. 181 (1994), 9-29. 
Temperature, Desiccation, and Species Performance Trends ...

[2] A. I. Borthagaray and A. Carranza, Mussels as ecosystem engineers: their contribution to species richness in a rocky littoral community, Acta Oecol. 31 (2007), 243-250.

[3] C. E. Braby, Cold stress, Encyclopedia of Tidepools and Rocky Shores, M. W. Denny and S. D. Gaines, eds., University of California Press, Berkeley, 2007, pp. 148-150.

[4] J. F. Bruno, J. J. Stachowicz and M. D. Bertness, Inclusion of facilitation into ecological theory, Trends Ecol. Evol. 18 (2003), 119-125.

[5] S. H. Chu, Q. S. Zhang, S. K. Liu, Y. Z. Tang, S. B. Zhang, Z. C. Lu and Y. Q. $\mathrm{Yu}$, Tolerance of Sargassum thunbergii germlings to thermal, osmotic and desiccation stress, Aquat. Bot. 96 (2012), 1-6.

[6] M. A. Crenshaw and J. M. Neff, Decalcification at the mantle-shell interface in mollusks, Am. Zool. 9 (1969), 881-885.

[7] M. W. Denny, L. J. H. Hunt, L. P. Miller and C. D. G. Harley, On the prediction of extreme ecological events, Ecol. Monogr. 79 (2009), 397-421.

[8] L. K. Eckersley and D. J. Garbary, Developmental and environmental sources of variation on annual growth increments of Ascophyllum nodosum (Phaeophyceae), Algae 22 (2007), 107-116.

[9] K. M. Fedorka, W. E. Winterhalter, K. L. Shaw, W. R. Brogan and T. A. Mousseau, The role of gene flow asymmetry along an environmental gradient in constraining local adaptation and range expansion, J. Evol. Biol. 25 (2012), 16761685.

[10] S. C. Hand and M. A. Menze, Desiccation stress, Encyclopedia of Tidepools and Rocky Shores, M. W. Denny and S. D. Gaines, eds., University of California Press, Berkeley, 2007, pp. 173-177.

[11] R. N. Haring, M. N. Dethier and S. L. Williams, Desiccation facilitates waveinduced mortality of the intertidal alga Fucus gardneri, Mar. Ecol. Prog. Ser. 232 (2002), 75-82.

[12] S. C. Johnson and R. E. Scheibling, Structure and dynamics of epifaunal assemblages on intertidal macroalgae Ascophyllum nodosum and Fucus vesiculosus in Nova Scotia, Canada, Mar. Ecol. Prog. Ser. 37 (1987), 209-227.

[13] N. Kautsky, Growth and size structure in a Baltic Mytilus edulis population, Mar. Biol. 68 (1982), 117-133.

[14] G. A. Knox, The Ecology of Seashores, CRC Press, Boca Raton, 2001. 
[15] C. S. Lobban and P. J. Harrison, Seaweed Ecology and Physiology, Cambridge University Press, Cambridge, 1994.

[16] B. A. Menge and G. M. Branch, Rocky intertidal communities, Marine Community Ecology, M. D. Bertness, S. D. Gaines and M. E. Hay, eds., Sinauer, Sunderland, 2001, pp. 221-251.

[17] B. A. Menge, B. A. Daley, P. A. Wheeler, E. Dahlhoff, E. Sanford and P. T. Strub, Benthic-pelagic links and rocky intertidal communities: bottom-up effects on top-down control?, Proc. Natl. Acad. Sci. U. S. A. 94 (1997), 14530-14535.

[18] B. A. Menge and J. P. Sutherland, Community regulation: variation in disturbance, competition, and predation in relation to environmental stress and recruitment, Am. Nat. 130 (1987), 730-757.

[19] R. Nagarajan, S. E. G. Lea and J. D. Goss-Custard, Seasonal variations in mussel, Mytilus edulis L., shell thickness and strength and their ecological implications, J. Exp. Mar. Biol. Ecol. 339 (2006), 241-250.

[20] G. P. Quinn and M. J. Keough, Experimental Design and Data Analysis for Biologists, Cambridge University Press, Cambridge, 2002.

[21] R. A. Scrosati, Subarctic shores without an ice foot: low extremes in intertidal temperature during winter, Curr. Develop. Oceanogr. 3 (2011), 153-160.

[22] R. Scrosati and R. E. DeWreede, The impact of frond crowding on frond bleaching in the clonal intertidal alga Mazzaella cornucopiae (Rhodophyta) from British Columbia, Canada, J. Phycol. 34 (1998), 228-232.

[23] R. Scrosati and L. K. Eckersley, Thermal insulation of the intertidal zone by the ice foot, J. Sea Res. 58 (2007), 331-334.

[24] R. Scrosati and C. Heaven, Field technique to quantify intensity of scouring by sea ice in rocky intertidal habitats, Mar. Ecol. Prog. Ser. 320 (2006), 293-295.

[25] R. Scrosati and C. Heaven, Spatial trends in community richness, diversity, and evenness across rocky intertidal environmental stress gradients in eastern Canada, Mar. Ecol. Prog. Ser. 342 (2007), 1-14.

[26] R. A. Scrosati, B. van Genne, C. S. Heaven and C. A. Watt, Species richness and diversity in different functional groups across environmental stress gradients: a model for marine rocky shores, Ecography 34 (2011), 151-161.

[27] G. Somero, Heat stress, Encyclopedia of Tidepools and Rocky Shores, M. W. Denny and S. D. Gaines, eds., University of California Press, Berkeley, 2007, pp. 266-270. 
[28] R. Stafford and M. S. Davies, Spatial patchiness of epilithic biofilm caused by refuge-inhabiting high-shore gastropods, Hydrobiologia 545 (2005), 279-287.

[29] S. G. Whitaker, J. R. Smith and S. N. Murray, Reestablishment of the southern California rocky intertidal brown alga Silvetia compressa: an experimental investigation of techniques and abiotic and biotic factors that affect restoration success, Restor. Ecol. 18 (2010), 18-26. 
Table 1. Summary results on temperature traits (in ${ }^{\circ} \mathrm{C}$; mean \pm SE for all traits, except for extreme maximum and minimum values) measured at the low, middle, and high intertidal zones on a subpolar NW Atlantic shore in summer

\begin{tabular}{lccc}
\hline & Low zone & Middle zone & High zone \\
\hline Extreme maximum & 35.5 & 43.9 & 46.7 \\
Mean daily maximum & $21.7 \pm 0.3$ & $27.4 \pm 0.7$ & $32.2 \pm 0.7$ \\
Overall daily mean & $19.4 \pm 0.1$ & $20.3 \pm 0.2$ & $21.5 \pm 0.2$ \\
Mean daily minimum & $18.3 \pm 0.1$ & $17.4 \pm 0.2$ & $15.8 \pm 0.2$ \\
Extreme minimum & 16.9 & 11.1 & 10.8 \\
Mean daily range & $3.4 \pm 0.2$ & $10.0 \pm 0.6$ & $16.4 \pm 0.7$ \\
\hline
\end{tabular}

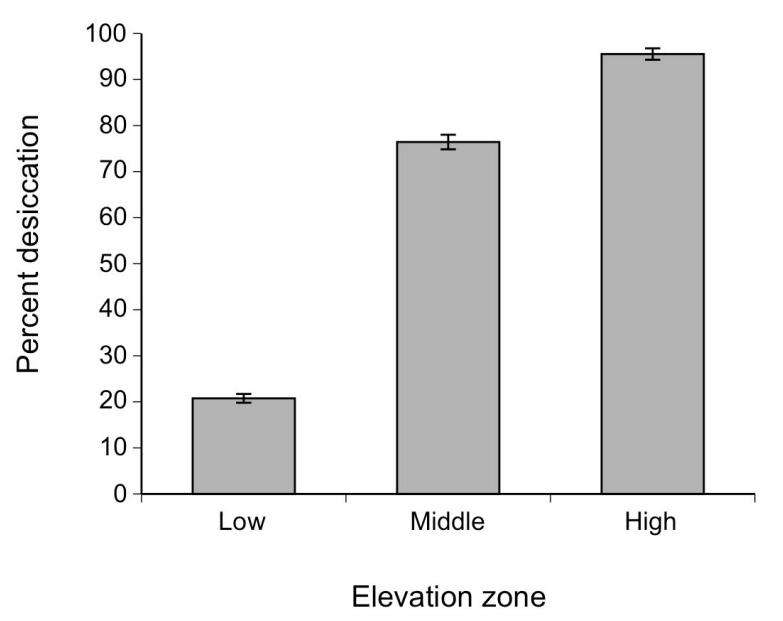

Figure 1. Changes in desiccation rate (expressed as \% of the total water content lost during the low tide; mean $\pm \mathrm{SE}$ ) along the intertidal elevation gradient. 


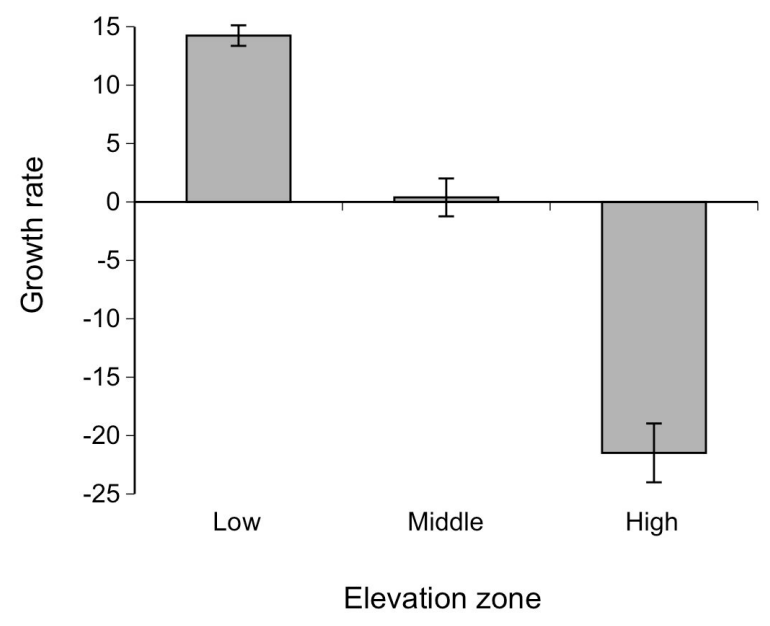

Figure 2. Changes in growth rate of the seaweed Ascophyllum nodosum (expressed in $\mathrm{mm}$; mean $\pm \mathrm{SE}$ ) along the intertidal elevation gradient.

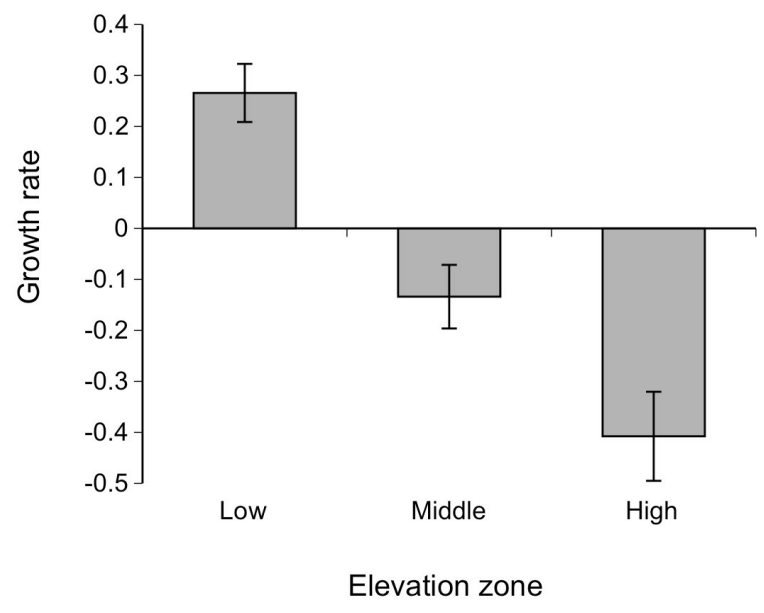

Figure 3. Changes in growth rate of the mussel Mytilus edulis (expressed in $\mathrm{mm}$; mean $\pm \mathrm{SE}$ ) along the intertidal elevation gradient. 